\title{
Research on the Frame Design and the Key Technology of Smart Tourism System in Scenic Area
}

\author{
Yong $\mathrm{Yu}$ \\ Business College \\ Yantai Nanshang University \\ Yantai, China
}

\author{
Hui Wang \\ Engineering College \\ Yantai Nanshang University \\ Yantai, China
}

\begin{abstract}
In respect to the smart tourism in scenic area, this paper analyzes the concept, sets forth the development status and completes the frame design. It puts forward the three modules, including the application system, the basic supporting system and the guarantee system, and further explains internet of things, cloud computing, big data, mobile internet and key virtual reality technology of smart tourism in scenic area.
\end{abstract}

Keywords-smart tourism in scenic area; frame design; key technology

\section{INTRODUCTIONA}

At present, there isn't a unified definition on the smart tourism in scenic area. It includes the following statements. First, "smart tourism in scenic area" refers to the innovationtype scenic area formed under the background of transformation from "digital" to "smart", carrying out thorough perception, wide interconnection and scientific management of environment, society and economy. Second, the nature of smart tourism in scenic area is to replace the traditional tasks requiring judgment and decision of people with intelligent technology and scientific management theory, so as to optimize the business, realize the electronic, momentary, convenient, systematic, accurate and efficient management and service of scenic areas and create efficient smart scenic areas with standard operation. Third, the core of "smart tourism in scenic area" construction is to achieve allround, systematic and timely perception and visual management of resources and environment, infrastructure, tourists' activities and risk of disasters through integration of sensor network, internet of things, internet and spatial information technology, improving the automation of information collection, transmission, processing and analysis, so as to realize comprehensive, real-time, interactive, elaborate and sustainable informatization management and service. According to the above expression, in narrow sense, the smart tourism in scenic area focuses on technical factors, including application of internet of things, perception and recognition technology, network and communication technology, cloud computing technology and virtual reality technology; in broad sense, the smart tourism in scenic area emphasizes multiple factors like highly integrate the scientific management theory with modern information technology and improve the

Fund project: Yantai Social Sciences Planning Project (ytsk2016-R139); Humanities and Social Sciences Research Project of Shandong Higher School(J15WB94) operation efficiency, in order to realize low carbon smart operation with harmonious development of man and nature, the comprehensive, coordinate and sustainable development of economy, society and environment.

\section{THE DEVELOPMENT STATUS OF SMART TOURISM IN SCENIC AREA}

IBM Company put forward "Smart Planet" and "Smart City" in 2008. Smart City refers to the specific embodiment of Smart Planet. It is only a business plan and project raised by the company. As for the research and practice on applying information technology to tourist industry, foreign countries start earlier than us. In 2001, EU launched the project of "Build User-friendly Personalized Mobile Travel Service"; in 2005, Steamboat ski resort in Colorado used RFID locating device feedback system for users-Mountain Watch, which can monitor tourists' position real-timely, recommend skiing route and tell tourists' consumption situation, providing safe and convenient IT-enabled service. Intelligent guide system is launched on the basis of $3 \mathrm{G}$ communication system in London for self-help tourists to travel freely. "Mobile Travel Information Service Project" launched by Korea National Tourism Organization enables tourists to enjoy consultation services through network or mobile network like tourism information inquiry and online booking.

Our country has devoted to the development of smart tourism in recent years, so as to strengthen the tourism and successfully transform tourism industry from traditional service industry to modern service industry. The purpose is to construct enterprises and cities of smart tourism and build tourism basic information database and platform for exchange and sharing of tourism basic information. It extends to national scope, significantly improving the informatization level of tourist industry, exceeding the overall informatization level of service industry. Developed areas and large scenic spots start the development and application of smart tourism early. In recent years, the construction of "smart tourism in scenic area" has become a new trend of tourist industry development in our country. In September 2015, National Tourism Administration issued the Tourism plus Internet Action Plan and defined all national 5A level scenic spots will be built into "smart tourism scenic area" by 2018; all national 4A level scenic spots will realize full coverage of free WIFI, intelligent tourism guide, electronic introduction, online booking and information push 
by 2020 . According to statistics, there are two hundred and thirteen 5A level scenic spots, six hundred and seventeen 4A level scenic spots and countless $3 \mathrm{~A}$ level scenic spots by the end of 2015. Currently, the smart tourism in scenic area mainly involves: tourism application of virtual imaging, applications based on wireless position service, electronic map and intelligent management systems in and outside the scenic areas. The construction of smart tourism in scenic area includes hardware facilities like internet of things, sensor network and communication network and software facilities like data center, application server system, sharing service platform and integrated decision support system. Core information technologies like internet, internet of things, cloud computing and mobile communication and advanced development idea can promote greening, modernization and sustainable development of tourist industry, improving tourism service quality and optimizing tourism management. Besides, it helps to save the time of tourists, enterprises and government and the cost of space and information transmission and reduce wasting of resources, roundly improving social, economic and environmental benefits of tourist industry.

\section{THE FRAME DESIGN OF SMART TOURISM SYSTEM IN SCENIC AREA}

\section{A. The Application System of Smart Tourism in Scenic Area}

1) The.service system of smart tourism in scenic area: The smart tourism service system in scenic areas uses modern information technology to serve tourists, meeting their requirements, shortening their time in waiting and improving tourist experience. In order to solve the problem of inconvenience caused by increasing number of tourists in peak season, the construction of smart tourism service system in scenic areas shall: realize full coverage of Wifi to provide internet service; develop APP for tourists to consume conveniently; recommend virtual tourism to avoid the peak season.

2) The marketing system of smart tourism in scenic area: It bases on traditional marketing and roundly improves efficiency and effectiveness of tourism marketing through channel innovation, method innovation and technical innovation, so as to better popularize tourism resources and sell tourism products. Compared with traditional tourism marketing, the smart tourism in scenic area better seizes new media and caters to tourists' habit, covering the whole tourism process, positioning accurately and focusing on marketing effects. It includes network marketing, e-commerce and customer relationship management of smart tourism in scenic area.

3) The management system of smart tourism in scenic area: Management system of smart tourism in scenic area is the platform for controllers of scenic areas to provide intelligent management. It can actively get tourist information, complete data accumulation and analysis system of tourists and roundly know about customers' changes in requirements, so that controllers can analyze and predict tourism market, formulate policies and take corresponding measures. The management system of scenic area smart system includes automatic fare collection system, tourist traffic monitoring system, tourism statistical analysis system, rescue system and comprehensive dispatching system.

\section{B. The Basic Support System of Smart Tourism in Scenic Area}

1) Information infrastructure: Automatic information acquisition is to use information collection technology and equipment like RS and RFID to collect the first-hand information as the front-end information entry of smart tourism system. The information can be transmitted efficiently through network and related servers.

2) Data infrastructure: Data infrastructure of smart tourism in scenic area is the core foundation of all smart tourism items as well as the most important strategic resources. In the construction of data layer, it is necessary to effectively organize, integrate and use data from the overall perspective and furthest excavate data value. Data integrated management refers to classify the collected data through data warehouse according to different properties, in order to improve its service efficiency.

3) Shared service facility: Information sharing and service platform bases on cloud computing, further computes and edits data to provide technology and information service for three application systems of scenic area smart system and realize information management through data output.

\section{The Guarantee System of Smart Tourism in Scenic Area}

1) Policy guarantee: Special policies must be formulated in scenic areas to guarantee overall construction of smart tourism, covering information infrastructure, data infrastructure, function positioning of tourist information center, management of IT project, construction and management of shared service infrastructure.

2) Fund guarantee: Make the best of self-owned funds, actively expand financing channels and win over financial supports like financial fund, research project, bank loan, enterprise investment and social financing to provide longterm and stable fund guarantee for the construction of smart tourism in scenic area.

3) Technical support: Technical support is the prerequisite of smart tourism in scenic area construction. Smart tourism can realize with the help of technology platform. Internet, internet of things, cloud computing and geographical information system can be applied to smart tourism better. Unified information standards shall be established for related software of smart tourism in scenic area, the data information used by internet and wireless internet to let more people participate in the collection and classification of information, realize interconnection of all items and subsystems and gradually improve requirement communication and development efficiency.

4) Talent guarantee: In order to meet the requirements of smart tourism in scenic area construction, on the one hand, conform to the demands of business management and introduce high-level professionals by stages; on the other hand, intensify the training of existing technical personnel about 
related policies and regulations as well as technical specification so as to improve their professional level.

\section{THE KEY TECHNOLOGIES OF SMART TOURISM IN SCENIC AREA}

\section{A. Internet of Things}

Internet of things can be used to carry out real-time interconnection of emergency and service facilities in scenic areas, provide personalized tourism service according to user demand and improve user experience. The scheme of internet of things for mobile and fixed facilities can be realized through analyzing vehicles in scenic areas, emergency facilities, position and state of service personnel. In "Smart Tourism", the internet of things has broad application prospects in entrance guard, security and protection, self-guided tour and environmental monitoring.

\section{B. Cloud Computing}

Cloud computing can be used for regional tourism information platform, large commercial tourism website and data center of large travel agencies. For regional tourism information platform, the cloud computing can improve its performance and promotes the integration of local tourism information resources. For large commercial tourism websites, the cloud computing can adjust and compute resources according to page view to reduce operating costs. For large travel agencies like China International Travel Service, data center based on cloud computing can realize the integration of business and finance and improve group control ability. For small and medium travel agencies, the tourism information service platform based on cloud computing can be used so that they don't need to buy software and hardware, which reduce the information threshold.

\section{Big Data Technology}

Big data refers to data set that it is incapable to capture, manage and deal with its contents within certain time. Data mining technology can be used to analyze tourists' behaviors, including tourist destination area, consumption tendency of six important parts of food, accommodation, transportation, traveling, shopping and entertainment in tourism industry, tourist consumption satisfaction and tourist spatial behavior (including traveling behavior, choice behaviors of tourist destinations, tourist routes and tourist attractions). Big data technology can improve the capacity to deal with tourism data and better serve tourists.

\section{Mobile Communication Technology}

Mobile communication technology enables tourists to get tourism information resources whenever and wherever possible. For example, tourists can use mobile intelligent terminals like iPhone to check tourism information, book hotel, book airline ticket, book tickets and query the current geographic location. When traveling abroad, tourists can carry out conversion of exchange rate, language translation and map query on iPhone. They can communicate with foreigners successfully with the help of automatic translation function of multiple languages.

\section{E. Virtual Reality Technology}

Virtual reality technology can be introduced to realize construction and roaming of complicated tourism virtual scene. It can get vivid virtual tourism effect and realize construction, roaming and interconnection of virtual scene of real tourist destination. Technical schemes of virtual tourism can be established to realize online virtual tourism and make up for the deficiencies of existing tourism information system. Tourism information products can be used to provide tourists with panorama roaming of virtual tourist attractions and service facilities.

\section{CONCLUSION}

With the soaring development of information technology and the proposal of delicacy management and service concept, the construction of smart tourism in scenic area has become an irresistible trend. With the help of internet of things, cloud computing, big data technology, portable intelligent terminal and communication network, smart tourism in scenic area can realize deeper and experience-oriented tourist activities, more personalized and real-time tourism enterprise management activities, more systematic and sustainable tourism administrative activities and more harmonious and tolerant relationship between residents of tourist destinations and tourists, as well as deep development of modern tourism. This article analyzes the development status of smart tourism in domestic and foreign scenic areas, and core technology of smart tourism and establishes smart tourism in scenic area system. However, long-term unremitting efforts are required for construction of smart tourism system. All kinds of resources shall be integrated, including technical breakthrough, transformation of organization structure, coordination of relationships between different departments, units and interest groups, as well as management of relationships between protection and development, short-term construction and longterm development.

\section{REFERENCES}

[1] Li Yunpeng. Discussion on the Concept of Smart Tourism under the Perspective of Tourism Information Service [J], Tourism Tribune, 2014(5)

[2] Hu Beiming, Zhang Linjing. Construction of Smart Tourism System in Tourist Destination in the Self-driving Era-Research on the Basis of Content Analysis [J], Journal of Sichuan University of Science and Engineering (Social Sciences Edition), 2016(5)

[3] Liao Weijun. Exploration on the "Smart Tourism" Based on the Internet of Things [J], Ecological Economy, 2013(7)

[4] Pang Zhaoling. Research on the Frame Construction of Smart Tourism System Based on the Service Function [J], Journal of Huangshan University, 2015(2)

[5] Liu Lining. Research on the Evaluation Index System of Smart Tourism [J], Science and Technology Management Research, 2013(6) 